Thorax (1971), 26, 223.

\title{
Laceration of the lung following blunt trauma
}

\author{
K. M O G H IS S I ${ }^{1}$ \\ Hammersmith Hospital, Royal Post-graduate Medical School, Du Cane Road, London W.12
}

\begin{abstract}
Laceration of the lung was found in $4.4 \%$ of cases of chest injury caused by blunt trauma admitted to two thoracic centres. Criteria for accurate diagnosis are presented. It is suggested that thoracotomy should be considered and carried out as soon as possible when the diagnosis is made. It was found that cases treated with early thoracotomy did not require any pulmonary resection. In others, lack of prompt diagnosis and a conservative approach led eventually to loss of lung parenchyma.
\end{abstract}

In civilian life chest injuries are responsible for a high mortality and morbidity in victims of road traffic accidents. A good deal has been written about those injuries which result in an unstable chest with paradoxical chest movement and consequent respiratory difficulties and a higher fatal outcome (Barrett, 1960 ; Windsor and Dwyer, 1961 ; Sellors, 1961).

More trivial injuries in the form of isolated rib fractures with minor visceral damage are also well documented and easy to diagnose and manage (Brown and Boyd, 1952 ; Glennie, 1965 ; Bassett, Gibson, and Wilson, 1968).

Laceration of the lung, on the other hand, has received little attention. This type of injury is not common. Nevertheless it is our belief that it should be diagnosed early and treated by thoracotomy. By so doing, little or no lung tissue need be sacrificed, whereas late diagnosis and a conservative approach lead eventually to surgery with a more substantial loss of pulmonary parenchyma.

In this paper we discuss the diagnosis and management of laceration of the lung caused by blunt trauma to the chest.

\section{SUBJECTS}

A total of 182 patients with a variety of chest injuries caused by blunt trauma in two chest surgery centres ${ }^{2}$ in England were studied. These patients were obviously those who required admission to such centres, i.e., their injuries were in some way complicated. A rational, though empirical, classification was adopted for working out these cases (Table I).

Eight patients $(4 \cdot 4 \%)$ suffered laceration of the lung, proved by thoracotomy or postmortem

1Present address: Castle Hill Hospital, Cottingham, B. Yorkshire. 2Wessex Regional Cardiothoracic Centre at Southampton Chest Hospital and Harefield Hospital, Harefield, Middlesex.
T A B L E I

TYPE OF CHEST INJURY IN 182 PATIENTS

\begin{tabular}{|c|c|c|c|c|c|}
\hline \multicolumn{4}{|c|}{ Type of Injury } & No. & $\%$ \\
\hline $\begin{array}{l}\text { With stable chest } \\
\text { Simple (isolated ribs) } \\
\text { Complicated (bony and } \\
\text { Haemopneumothorax } \\
\text { Lung contusion } \\
\text { Lung laceration } \\
\text { Ruptured diaphragm } \\
\text { Heart or major vessel }\end{array}$ & $\begin{array}{l}\because \\
1 \text { viscera } \\
\therefore \\
\therefore \\
\text { ls }\end{array}$ & $\begin{array}{l}\cdots \\
\because \\
\cdots \\
\cdots \\
\cdots\end{array}$ & $\begin{array}{l}\cdots \\
\ddot{*} \\
\cdots \\
\cdots \\
\cdots\end{array}$ & $\begin{array}{r}156 \\
48 \\
108 \\
72 \\
16 \\
8 \\
7 \\
5\end{array}$ & $\begin{array}{r}85 \cdot 5 \\
26 \cdot 5 \\
59 \cdot 0 \\
39 \cdot 5 \\
8 \cdot 8 \\
4 \cdot 4 \\
3 \cdot 8 \\
2 \cdot 8\end{array}$ \\
\hline $\begin{array}{l}\text { With unstable chest } \\
\text { Simple (bony) } \quad \text {. } \\
\text { Complicated } \\
\text { Thoraco-abdominal } \\
\text { Thoracic and head }\end{array}$ & 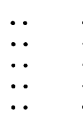 & $\begin{array}{l}\ddot{*} \\
\ddot{*} \\
\cdots \\
\cdots\end{array}$ & $\begin{array}{l}\cdots \\
\cdots \\
\cdots \\
\cdots\end{array}$ & $\begin{array}{r}26 \\
21 \\
5 \\
3 \\
2\end{array}$ & $\begin{array}{r}14 \cdot 5 \\
11 \cdot 5 \\
2 \cdot 8 \\
1 \cdot 7 \\
1 \cdot 1\end{array}$ \\
\hline
\end{tabular}

examination. All these eight patients had been involved in road traffic accidents. Two patients were pedestrians hit or run over by a motor vehicle. Three patients received their injuries by steering wheel trauma. Three patients were motor-cyclists in collision with a motor vehicle.

Table II presents ages and important symptoms and signs in these patients at the time of admission.

Shock was present in four patients suffering from additional injuries with a considerable loss of blood or body fluid. Cyanosis was not a constant finding and was recorded only in those with multiple injuries. In two patients (1 and 3) cyanosis developed later. This is interesting because these two were treated conservatively at first. Expanding intrapulmonary haematoma and an increasing degree of pulmonary collapse were thought to be the cause of later hypoxaemia and the desaturation of blood.

Haemoptysis of various magnitude was present in every patient with lacerated lung. In four patients $(4,5,6$, and 7$)$ bronchoscopy was performed early (within hours of accident), and blood 
T A B LE I I

SYMPTOMS AND SIGNS OF PATIENTS WITH LACERATED LUNG

\begin{tabular}{|c|c|c|c|c|c|c|c|c|}
\hline Case & Age & Sex & Shock & Cyanosis & $\begin{array}{l}\text { Haemo- } \\
\text { ptysis }\end{array}$ & $\begin{array}{c}\text { Surgical } \\
\text { Emphysema }\end{array}$ & $\begin{array}{l}\text { Paradoxical } \\
\text { Breathing }\end{array}$ & Injuries \\
\hline $\mathbf{1}$ & $\begin{array}{l}23 \\
50\end{array}$ & $\begin{array}{l}\mathbf{M} \\
\mathbf{M}\end{array}$ & $\overline{+}$ & $\begin{array}{c}+ \text { late }) \\
+\end{array}$ & + & \pm & - & $\begin{array}{l}\text { Fractured ribs }(2-5) \text {, laceration } R L L \\
\text { Fractured ribs }(8-11) \text {, skeletal fractures, laceration } L L L \text {, } \\
\text { ruptured spleen }\end{array}$ \\
\hline $\begin{array}{l}3 \\
4 \\
5 \\
6 \\
7\end{array}$ & $\begin{array}{l}20 \\
11 \\
18 \\
14 \\
36\end{array}$ & $\begin{array}{l}\mathbf{M} \\
\mathbf{M} \\
\mathbf{M} \\
\mathbf{F}\end{array}$ & $\begin{array}{l}\overline{+} \\
\bar{t}\end{array}$ & $\begin{array}{c}(+ \text { late }) \\
+ \\
- \\
+\end{array}$ & $\begin{array}{l}+ \\
+ \\
+ \\
+ \\
+\end{array}$ & $\begin{array}{l}\overline{+} \\
\overline{-}\end{array}$ & $\begin{array}{l}- \\
- \\
-\end{array}$ & $\begin{array}{l}\text { Fractured ribs }(2-4) \text {, laceration } L U L \\
\text { Fractured ribs, ruptured RUL bronchus, laceration RLL } \\
\text { Fractured ribs }(9-11) \text {, laceration } L L L \\
\text { Fractured ribs ( } 2-6) \text {, laceration } R M L \text { and RLL } \\
\text { Fractured ribs (6-11), fractured humerus, multiple lacera- } \\
\text { tions, lacerated LLL, ruptured diaphragm }\end{array}$ \\
\hline 8 & 40 & $\mathbf{M}$ & + & + & + & + & - & $\begin{array}{l}\text { Multiple visceral injuries, laceration lung, ruptured } \\
\text { abdominal viscera and aorta (PM findings) }\end{array}$ \\
\hline
\end{tabular}

was seen seeping from a segmental or lobar bronchus corresponding to the site of injury. In three patients bronchoscopy was performed later and localization of the bleeding was less clear. Haemoptysis is thus an important lead and a constant finding in these cases.

Surgical subcutaneous emphysema was present in three patients. Judging from our other cases of chest injury it appears that the presence of surgical emphysema does not always indicate serious pulmonary damage, and its absence does not rule out lacerated lung.

Paradoxical breathing has been constantly absent in all our cases. Table I shows that in our series of 182 cases of chest injury, 26 patients presented with an unstable chest caused by multiple fractures of the ribs or sternum. In none of these was pulmonary laceration recorded. It therefore appears that if at the moment of impact the integrity of the cage is disrupted the major stress is removed: the intrapulmonary tension is not then sufficient to cause laceration. On the other hand, when the chest remains stable following an impact of great force, the major stress is transmitted to the interior. This will increase the intrathoracic pressure which in turn causes the bronchi to burst or the lung to tear, particularly if the glottic 'safety valve' is closed. It is interesting to note that in only one case (case 1) in this series could the tears in the lung have been attributed to a fractured rib penetrating into the lung. In all the others there was clear evidence that the lung had literally burst, and the lacerations were not necessarily near fractured ribs.

RADIOLOGICAL FINDINGS All cases sustained rib fractures, usually in one place-the posterior end. The number of ribs fractured did not exceed five.

Haemothorax of variable size was present in every case. Pneumothorax was also present in all.
The most characteristic radiological features (Figs 1, 2, and 3) were: 1. a shallow pneumothorax. There was only a $3.0-5.0 \mathrm{~cm}$ space between the apices of the thorax and the lung in all patients (except cases 4 and 8 , who had, in addition to the laceration, either avulsion of a lobe or a ruptured bronchus); 2 . haemothorax of varying size but never more than $500-700 \mathrm{ml}$; 3. a fairly well defined opacity in the lung substance with upward convexity. The lower part of this opacity merged indistinctly with the basal haemothorax, even when the lower lobe was unaffected (Fig. 2).

These radiological findings are, in our experience, diagnostic and can in most cases be differentiated from other injuries such as vascular injuries with a large haemothorax, pulmonary contusion with its patchy infiltration, or ruptured trachea and bronchus, already well documented in the literature (DeMuth and Smith, 1965 ; Stevens and Templeton, 1965 ; Chesterman and Satsangi, 1966 ; Larizadeh, 1966). In our cases, after insertion of an intercostal tube and drainage of haemopneumothorax there was little change in the radiological appearances of the pulmonary opacity, whereas in a simple haemothorax following intercostal drainage the chest radiograph usually shows considerable change and clearing.

INDICATIONS FOR SURGERY Seven patients had a thoracotomy. Four patients $(4,5,6$, and 7 -Table III) were operated on within hours of admission. In these, early thoracotomy was performed because of persistent haemoptyses or air leak and the correct diagnosis of laceration of the lung was confirmed; no resection was necessary and debridement, haemostasis, and repair only was carried out. In three other cases $(1,2$, and 3 Table 1II) thoracotomies were performed later. In these, the failure of the lung to expand, evidence of extension of the lung opacity, deteriora- 


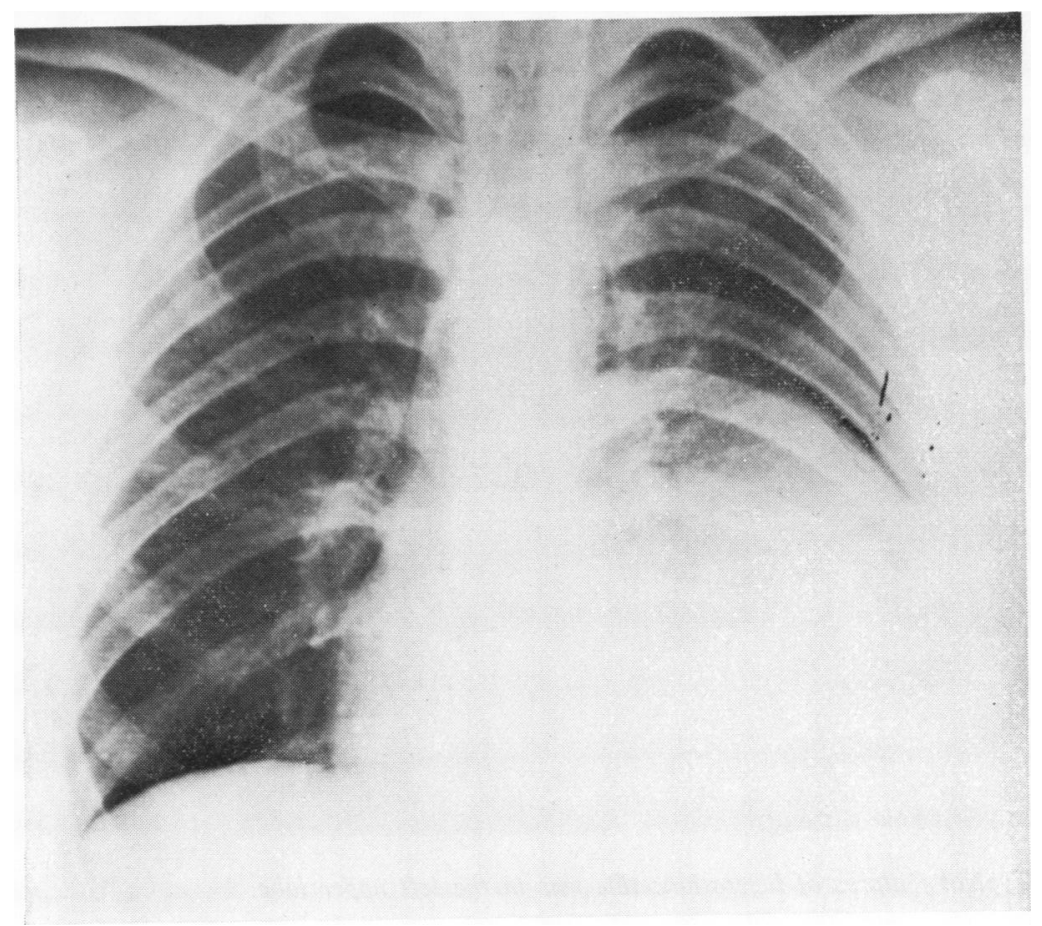

FIG. 1. Case 5. Typical triad of shallow pneumothorax, haemothorax, and a rounded opacity in the substance of the lung.

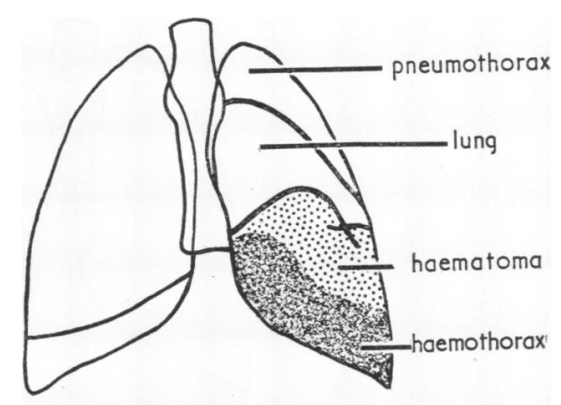

Fig 1

tion of respiration, and persistent small haemoptyses were the main reasons for stopping conservative treatment in favour of operation. The diagnosis was confirmed at operation in each case.

OPERATIVE FINDINGS The seven patients were operated on by three different surgeons. In each patient a major tear through the lung substance was found. In four early thoracotomy cases $(4,5$, 6 , and 7-Table III) no resection was required. In the three late thoracotomy cases $(1,2$, and 3$)$ a major resection had to be undertaken. It is relevant to record the operative and pathological findings in these three cases.
Case 1 The lower lobe of the lung had a tear leading into a cavity which was full of blood. The whole of the lobe was virtually destroyed. Right lower lobectomy was performed.

Case 2 There was a large tear in the left lower lobe, the basal segments of which were found to be almost completely haemorrhagic, forming a friable mass; no repair could be undertaken and a left lower lobectomy was performed. A report on the specimen removed read: 'The lobe has almost been torn across. The tissue is congested and haemorrhagic.' The histological report was as follows: 'The whole picture is that of haemor- 


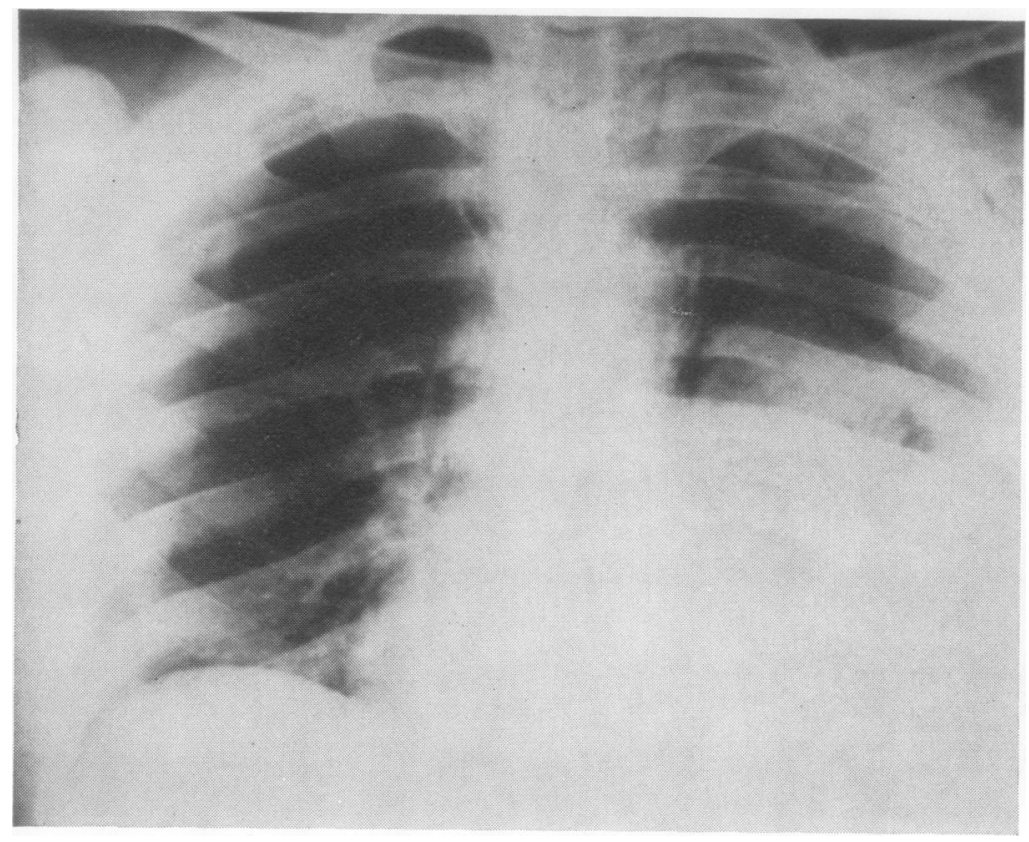

FIG. 2. Case 3. Typical features of laceration; this was in the left upper lobe.

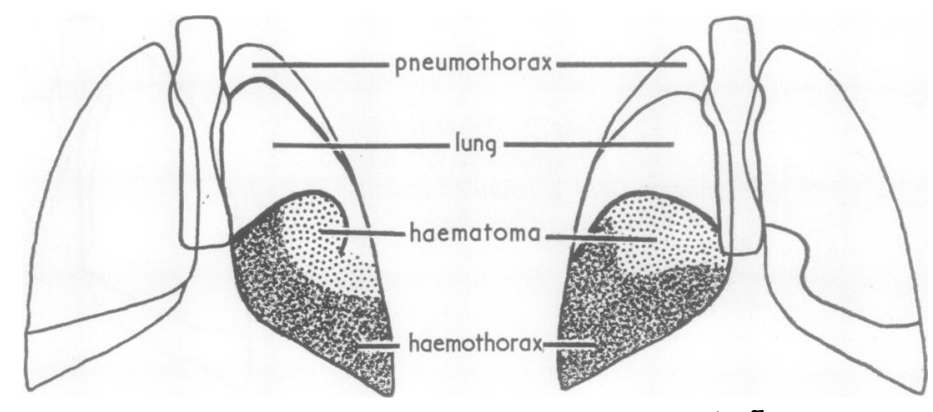

$\underline{\underline{F}} 9 \underline{2}$

Fig $\underline{3}$

T A B L E II I

LESIONS AND OPERATIONS IN CASES OF LACERATED LUNG

\begin{tabular}{|c|c|c|c|c|c|c|}
\hline Case & $\begin{array}{l}\text { Hospital } \\
\text { Stay (days) }\end{array}$ & Tracheostomy & Lung Lesion & $\begin{array}{l}\text { Delay before } \\
\text { Thoracotomy }\end{array}$ & Operation & Final Result \\
\hline 1 & 22 & - & Laceration RLL & 5 days & Right lower & Good \\
\hline $\begin{array}{l}2 \\
3 \\
4\end{array}$ & $\begin{array}{l}22 \\
35 \\
14\end{array}$ & $\stackrel{+}{ \pm}$ & $\begin{array}{l}\text { Laceration LLL } \\
\text { LUL laceration } \\
\text { Avulsed upper lobe; } \\
\text { lacerated } R L L\end{array}$ & $\begin{array}{l}3 \text { days } \\
3 \text { days } \\
3 \text { hours }\end{array}$ & $\begin{array}{l}\text { lobectomy } \\
\text { Left lower lobectomy } \\
\text { Left upper lobectomy } \\
\text { Repair RLL; } \\
\text { lobectomy }\end{array}$ & $\begin{array}{l}\text { Good } \\
\text { Good } \\
\text { Good }\end{array}$ \\
\hline $\begin{array}{l}5 \\
6\end{array}$ & $\begin{array}{l}11 \\
13\end{array}$ & - & $\begin{array}{l}\text { Lacerated LL lobe } \\
\text { Lacerated RML }\end{array}$ & $\begin{array}{l}2 \text { hours } \\
12 \text { hours }\end{array}$ & $\begin{array}{l}\text { right upper } \\
\text { Repair } \\
\text { Repair }\end{array}$ & $\begin{array}{l}\text { Good } \\
\text { Good }\end{array}$ \\
\hline $\begin{array}{l}7 \\
8\end{array}$ & $\begin{array}{c}25 \\
\text { Few hours }\end{array}$ & $\begin{array}{l}+ \\
+\end{array}$ & $\begin{array}{l}\text { Lacerated LLL } \\
\text { Lacerated LLL } \\
\text { and LUL }\end{array}$ & $\begin{array}{l}2 \text { hours } \\
\text { Necropsy findings }\end{array}$ & Repair & $\begin{array}{l}\text { Good } \\
\begin{array}{r}\text { Died before } \\
\text { operation }\end{array}\end{array}$ \\
\hline
\end{tabular}




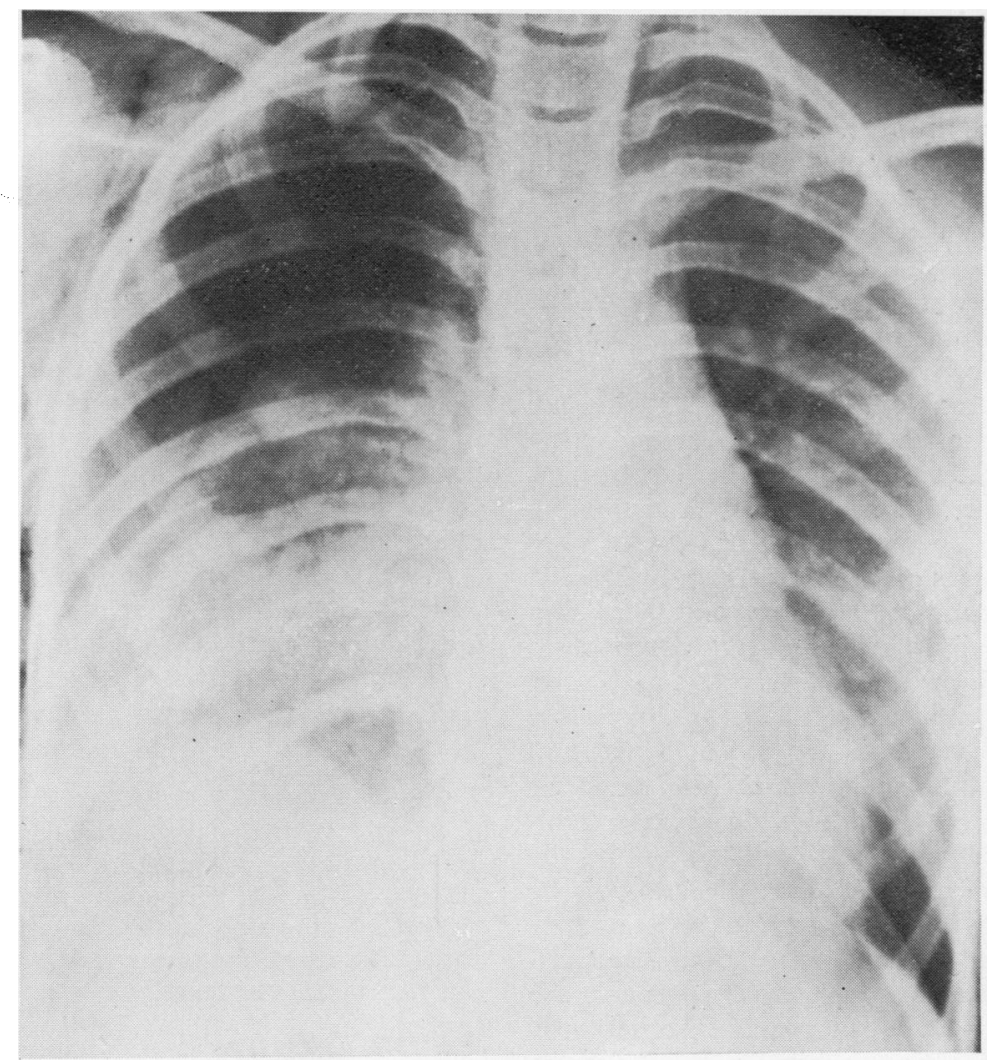

FIG. 3. Case 6. Features of laceration of lung, as described in the text.

rhage. The alveoli are distended with blood with resultant compression of the minor bronchi which are collapsed.'

Case 3 There was a laceration of the upper lobe ; this was leading to a cavity full of blood and surrounded by a friable mass of shattered parenchyma. A left upper lobectomy was performed. The specimen removed showed a ragged tear in the lung extending towards the hilum and to a cavity $12 \times 4 \times 2 \mathrm{~cm}$. Histological examination showed a traumatic rupture of a large branch of the pulmonary artery with extensive interstitial haemorrhage.

\section{MANAGEMENT AND DISCUSSION}

First aid and emergency measures in these cases are the same as for any major injury. Attention must be paid to relieving airway obstruction, treating shock, and alleviating pain by appropriate measures. Patients are then best examined and assessed according to the symptoms and signs already discussed.

In our experience it is unlikely that patients with lung laceration will have an unstable chestthis may be taken as a lead.

Patients with an unstable chest often require artificial respiratory help; so do some with extensive multiple associated injuries. Other chest injuries, including those with lung laceration, initially do not usually require any respiratory assistance. After a thorough clinical examination a chest radiograph is taken which will show the typical appearance in cases of laceration already pointed out. In this connexion it is important to recall that on admission the films are usually taken in the supine position, and pneumothorax may not easily be detected until some time has elapsed between the accident and the radiological examination. For the same reason the haemothorax may appear trivial on early films. 
As soon as possible an intercostal drain is inserted into the appropriate side of the pleural cavity under local anaesthesia and the haemopneumothorax is drained. This improves the patient's condition temporarily. A second radiograph should then be taken to assess the appearance after pleural drainage. The presence of haemoptysis necessitates bronchoscopy-this should be carried out early, within hours of the accident. Early bronchoscopy has the advantage that it shows the site of the bleeding before changes in the bronchial mucosa have time to develop. Later bronchoscopy necessitates suction of the clot and altered blood before visualization of the bleeding site. In such cases the adjoining mucosa is swollen and inflamed and may contain considerable amounts of thick secretion and blood clot. Once the diagnosis of major lung laceration has been made failure of early improvement in the patient's condition with conservative measures, persistent air leak, haemoptysis, and lung collapse indicate early thoracotomy. On the evidence presented we believe that in the majority of cases an early thoracotomy obviates or reduces to a minimum the need for lung resection. Bleeding into the surrounding segments and the pleura can be stopped and debridement can be satisfactorily carried out by early thoracotomy. The disadvantages of continuing a conservative approach are that a number of patients will require thoracotomy eventually because of continuous air leak, haemorrhage, and respiratory embarrassment, together with increasing radiological evidence of lung collapse. This delay leads to a more extensive resection and less possibility of reparative procedures. In three of our patients (1, 2 and 3-Table III) thoracotomy was performed after conservative treatment had failed. A major pulmonary resection then had to be carried out.

In four patients $(4,5,6$ and 7$)$ the diagnosis of laceration was established within hours of admission. Each patient was treated by an early thoracotomy, in which debridement, haemostasis, and reparative surgery could be undertaken. Only one (case 4) required major pulmonary excision because, in addition to the right lower lobe laceration, there was complete avulsion of the right upper lobe. Right upper lobectomy was performed.

Table III also shows that the duration of hospitalization in our patients has been longer in those at first treated conservatively. These three patients $(1,2$, and 3$)$ were in hospital for a total of 79 days, average $26 \cdot 3$ days per patient, whereas the other four patients $(4,5,6$, and 7$)$ were in for a total of 66 days, average 16.5 days per patient.

\section{CONCLUSION}

Our series of eight patients, although modest, shows that diagnosis can be made reasonably accurately at an early stage.

The most constant diagnostic features were a $\overrightarrow{\vec{x}}$ history of severe chest trauma causing fractured $\hat{O}^{\circ}$ ribs, but no flail chest; haemoptysis was always iv present ; shock and cyanosis and respiratory diffi- N culties were mostly present in those with associa- $\omega$ ted injuries. Chest radiographs characteristically 옥 showed haemopneumothorax and a large oval opacity in the lung substance. Bronchoscopy indicated the anatomical site of the bleeding.

It is suggested that thoracotomy at an early stage is the treatment of choice.

I am grateful to Mr. K. S. Mullard and Mr. I. K. R. McMillan for allowing me to study their cases at Southampton Chest Hospital. I am also grateful to Mr. J. W. Jackson and Mr. H. C. NohlOser for allowing me to study and include their patient. I should like to thank Miss Stephanie Nichols for secretarial assistance.

\section{REFERENCES}

Barrett, N. R. (1960). Early treatment of stove-in chest. Lancet, 1, 293.

Bassett, J. S., Gibson, R. D., and Wilson, R. F. (1968). Blunt injuries to the chest. J. Trauma, 8, 418.

Brown, R. B., and Boyd, S. A. (1952). Thoracotomy versus thoracentesis for the initial drainage of traumatic hemothorax and hemopneumothorax. U.S. armed Forces med. J., 3, 557.

Chesterman, J. T., and Satsangi, P. N. (1966). Rupture of 윽 the trachea and bronchi by closed injury. Thorax, 21, 21 .

DeMuth, W. E. (Jr.), and Smith, J. M. (1965). Pulmonary contusion. Amer. J. Surg., 109, 819.

Glennie, J. S. (1965). Thoracic trauma. In Thorax ed. $N$ d'Abreu, A. L. In Clinical Surgery, Edited by C. G. Rob and R. Smith. Vol. 5, p. 11. Butterworths, London.

Larizadeh, R. (1966). Rupture of the bronchus. Thorax, 21, 28.

Sellors, T. H. (1961). The management of chest injuries. Thorax, 16, 1.

Stevens, E., and Templeton, A. W. (1965). Traumatic ? nonpenetrating lung contusion. Radiology, 85, 247.

Windsor, H. M., and Dwyer, B. (1961). The crushed chest. $\frac{O}{\mathbb{D}}$ Thorax, 16, 3 . 